\title{
ENGLISH FOR SPECIFIC PURPOSES AND THE SECOND FOREIGN LANGUAGE: REACHING BEYOND LANGUAGE TRAINING IN BA PHILOLOGY STUDY PROGRAMME
}

\author{
Sigita Rackevičienè, Violeta Janulevičienè, Liudmila Mockienè \\ Institute of Humanities, Mykolas Romeris University, Vilnius, Lithuania \\ Phone+37052714588, E-mails: sigita.rackeviciene@mruni.eu; vjanul@mruni.eu; liudmila@mruni.eu
}

\begin{abstract}
The paper describes in detail a unique study programme of English for Specific Purposes and the Second Foreign Language created by the teaching staff of the Institute of Humanities, Mykolas Romeris University in Vilnius, Lithuania, to meet the expectations and requirements of the current/future labour market. The need for the programme arose from the requests of both possible applicants and employers. Since its launch in 2012 the programme gathered impetus and received considerable interest from abroad as well: there have been growing numbers of students from China, Japan, Norway, Israel, Ukraine, Belarus, Poland, etc. enrolling into the study programme. Additionally, this BA study programme was tailored to meet the needs of students from other faculties and opened as a minor studies programme for students majoring in law, business and public administration, communication. Within several years of the successful implementation a greater choice of second languages has been offered, namely, Korean, Norwegian, German, Spanish and French. The employment rate and feedback from the alumni of the programme and their employers testify the success of the BA programme in the area of ESP in terms of providing graduates with the indispensable multilingual, cultural and communicative competencies. This enables to maintain and develop the programme further on.
\end{abstract}

Key words: English for Specific Purposes, bachelor's degree study programme, multilingualism, soft skills competence

\section{INTRODUCTION}

At the beginning of the second decade in the new millennium there was an expressed need in Lithuania for applied approach to philology studies and apparent, though not formalised, perception of unfulfilled expectations of both university graduates in English philology and employers in different spheres of public and private institutions (e.g. law firms and courts of law; small and medium business enterprises, ministries and nongovernmental organisations). The dissatisfaction regarding the curricula of English philology studies was, mainly, with the following two aspects: the graduates' complaints focused on the extensive period of time required to get the knowledge of the specific field of work, i.e. law, business, public governance, etc., and mastering the conventions, terminology and genre peculiarities of the target discourse community. Furthermore, they were never confident that their self-acquired knowledge and skills are adequate for 
successful performance in job-related tasks. On the other hand, employers resented that the employed graduates do not possess the required knowledge of the field for the tasks of daily importance. Another common issue dealt with the enterprise costs related to the necessity of hiring two linguists: one for international communication in English and the other for the work assignments in German, French, Spanish, Norwegian or Korean.

Meantime, the studies in the EU countries were carried out which pointed out to the development of multilingualism as a core instrument for economic prosperity of the European countries. Economic prosperity was and is considered impossible without intercultural dialogue, and languages are the main tools which ensure smooth development of such dialogue. Therefore, the EU Commission in its Communication Multilingualism: an asset for Europe and a shared commitment (2008) called for "communication in mother tongue plus two languages" and encouraged the member states to consolidate all efforts to achieve this objective.

In 2011 responding to the calls described above and relying on the expertise acquired over the years, the department of foreign languages at Mykolas Romeris University undertook the initiative to develop two new Bachelor of Arts (BA) study programmes - English for Specific Purposes and the Second Foreign Language (ESPSFL) and Translation and Editing (TE). The staff of the Foreign languages department had an extensive 20 years expertise in teaching modern languages for specific purposes at Mykolas Romeris University, specialising in social sciences. The teachers have been notably proactive in search for innovative ways and methodologies in the field. They were constantly requested to assist in the specialised communication and translations for the faculties of law, economics, psychology, public security, public administration and the administration of the university.

The present paper highlights the research carried out on the need for language specialists in the Lithuanian labour market, development of the ESPSFL programme, its purpose and profile, assessment and feasibility of the programme results, including the employability of the programme graduates.

\section{ANALYSIS OF THE NEED FOR LANGUAGE SPECIALISTS IN THE LITHUANIAN LABOUR MARKET}

As a stepping-stone for the ESPESFL programme, a research was performed to determine the need for language specialists on the Lithuanian labour market and substantiate the rationale behind the idea of designing a more specialised bachelor's degree study programme in philology. The objectives of the research were to address the following issues: 1) which foreign languages are predominantly needed in the working environment by the Lithuanian businesses; 2) whether there is an expressed need for specialists who are able to communicate in the native language of foreign partners and have knowledge about their home country/region culture; 3 ) what advantages (if any) such specialists would bring to business; 3 ) what are the routine work assignments to be carried out in foreign languages and what skills (linguistic and soft transferable skills) they require.

Nearly 60 companies, small and medium-sized enterprises, media representatives, translation agencies, ministries and municipalities responded to the survey. The obtained data was analysed by quantitative and qualitative methods.

The findings of the research revealed the importance of the ability to communicate in two foreign languages was a considerable advantage in the Lithuanian labour market. 
Though English was and is the key required language, employees who are fluent in Russian, French, German, Polish and other languages are also needed vitally.

According to the employers, knowledge of the foreign partners' native language is of indispensable importance - it enables to collect the first-hand information about the country and its business environment, understand the mentality of the partners, foster formal and informal relationship and enjoy trustful cooperation. Thus, in order to be successful, companies need employees who are fluent not only in lingua franca, i.e. English, but also in the languages of the countries they do business with. Furthermore, the absolute numbers of the employers highlight the importance of cultural and social conventions knowledge of the countries they are doing business with.

The following citation (original formulation retained) serves as a typical response in the questionnaire comments: "While the cooperation with foreign partners is intensifying, businesses really need specialists who can communicate in several languages and have knowledge of foreign societies and their cultural characteristics. Foreign language and cultural knowledge is an essential tool in building and developing relationships with partners abroad".

Here is another citation from the employers' responses: "In my opinion, the broader the range of knowledge in this <language> field, the more information an employee can collect from a variety of sources. In addition to that, one can interact with the representatives of other countries not only in English but also in their own language, can have informal conversations, and, finally, through the shared language can adopt and assimilate cultural heritage of the other country, thus getting more mature as a person. That is equally important to both public and private sector."

It is emphasized that work assignments at the Lithuanian state and private institutions require high proficiency standard of foreign languages for professional purposes and communication. The employers indicated the following job-related tasks that are most often carried out in the foreign languages: socialising/communicating with an institution/ company guests, foreign partners and specialists; representation of an institution/company abroad; participation in international projects; collection and analysis of information; drafting documents; managing correspondence; writing papers; making presentations; translating and editing, which usually requires both linguistic/communicative skills and knowledge of the basics of business, law and public governance (Janulevičienè and Rackevičienè 2012).

Taking into account the issues stated above, a BA study programme English for Specific Purposes and the Second Foreign Language was meticulously developed and approved by the Centre of Quality Assessment in Higher Education in 2011. In 2012 the first admittance was announced. Sufficiently big numbers of students enrolled into the programme notwithstanding a rather fierce competition for the prospective students by long-established English philology study programmes in Vilnius University, Lithuanian University of Educational Sciences and other universities in Lithuania. 


\section{DesCRIPTION OF THE BA DEGREe STUdy PROGRAMME ENGLISH FOR SPECIFIC PURPOSES AND THE SECOND FOREIGN LANGUAGE}

\subsection{The purpose of the ESPSFL study programme and the competences developed}

The aim of the programme is two-fold. Firstly, it seeks to provide the students with the general philological education encompassing the basics of linguistics and literary sciences, comprehensive theoretical knowledge about the structure and functioning of the study languages (English and the second foreign language), as well as the knowledge about the literature and the culture of the countries of those studied languages. The second aim of the programme is of applied interdisciplinary nature: the programme aims to develop skills to communicate in two foreign languages used for specific purposes (public administration, business, finance and law) in work environment and to ensure smooth international communication in state institutions and private enterprises.

Thus, the programme focuses on development of the following competences:

\section{1) Multilingual Competence}

The ESPSFL study programme is based on the assumptions on and call for multilingualism, i.e. promoting linguistic diversity in societies and crossing the boundaries of nations and cultures by development of capacity to communicate in several languages (c.f. Aronin and Singleton 2012; Mahrer 2017). The multilingual competence has become a crucial competitive advantage in the global market and provides graduates with wider employment possibilities. In addition to English, graduates of the ESPSFL study programme acquire proficiency in another or even two more foreign languages, which ensures their competitiveness in the labour market. As a second foreign language students can choose either languages of global communication (French, German) or languages of narrower but dynamically developing communication that are continually crossing the national boundaries of the economically prosperous countries and are becoming increasingly important in the international arena (Korean, Norwegian). French and German are the working languages of the European Union institutions, they are the main tool of communication between the institutions of the European Union and are widely used in the global context. The ESPSFL study programme students predominantly choose to study these languages.

Prior to 2018, ESPSFL students were able to choose the Norwegian language studies as an elective subject (i.e. as a third foreign language). In 2018, upon the decision of the Committee of the ESPSFL study programme the Norwegian language was put on the list of second foreign languages for students to choose from. This decision was influenced by the demand for the Norwegian language in the labour market. The growing number of Scandinavian companies have been establishing their branches or subsidiaries in Lithuania, which serve customers in Scandinavia. Such units need staff with the competencies of communicating effectively in Scandinavian languages. Since 2017-2018, the international company Intrum has constantly contacted the programme managers, with job offers for current students and graduates who have studied Norwegian as their second or third foreign language. The year 2017 saw signing a co-operation agreement with this company. Meanwhile, similar cooperation is being developed with other Scandinavian international companies having headquarters in Lithuania.

Mykolas Romeris University focuses strongly on establishing and fostering relations with universities and cultural centers not only in Europe, but also in several Asian countries. In 2014, a European-Asian Knowledge Consortium: Social Technologies for 
Smart and Inclusive Society was established at Mykolas Romeris University. Simultaneously, in the same year of 2014, upon the initiative of Dongseo University (South Korea), the King Sejong Institute (KSI Vilnius) was set up at Mykolas Romeris University. The KSI Foundation is a public institution under the Ministry of Culture, Sports and Tourism structure in South Korea, the mission of which is to provide attractive and high-quality Korean language and cultural studies abroad. Since 2015, the ESPSFL programme has become the one-of-a kind Lithuanian study programme in philology which offers English and Korean combined language studies. Studies of the Korean language as a second foreign language have attracted an outstanding interest of potential students. This is a unique opportunity to develop skills and proficiency with the Korean native professionals attested by the KSI Foundation, to participate in cultural, scientific and artistic activities and events organized by the KSI.

\section{2) ESP and professional communication competence}

In the Republic of Lithuania the ESPSFL study programme is at the present moment the unique interdisciplinary bachelor study programme of applied nature in the field of philology. Students acquire not only general philological competences of two foreign languages, but also get subject-specific communication competence (in areas of public administration, business, finance, law) which enable them to actively participate in international public and private sector settings. The ESP is viewed by the practitioners and researchers worldwide as the language training directed towards enabling the learners to linguistically function in a target professional domain situation (c.f. Stojković 2018; Belcher 2009). The ESPSFL learners' basic professional in-field knowledge and communication competences are also developed according to the indicated requests of the potential and current employers. Implementers of the ESPSFL study programme maintain regular contacts with the graduates, monitor graduates' employment and career progression, visit their workplaces, survey their responsibilities and job functions. The data collected is used to develop both the overall study programme and particular subject objectives.

The practical implementation of the programme focuses on developing students' comprehension of forms and principles in spoken and written communication for specific purposes (e.g. public administration, business and law); developing students' skills in professional field information analysis and usage of proper subject-specific terminology; preparing students for international oral and written communication while drafting official documents and letters, taking part in business meetings, translating field literature, etc. The studies ensure ESPSFL study programme graduates' ability to work in a wide variety of spheres - culture and education, information centres, media companies, publishing houses, tourism agencies, translation agencies, international organisations, units of state departments, municipalities and business companies.

In their course papers and bachelor theses the ESPSFL students are encouraged to research contrastive interdisciplinary topics. These research areas are suggested and initially discussed with the social partners of the programme. The primary aim of the research carried out by the learners is to ensure that their research is applicable in practical settings, or the research results are useful for the developers of term databases, translators of specific texts and communication specialists in various specific professional areas. The presence of social partners is binding on the BA thesis defence committee and assessment of the research papers. The bachelor theses predominantly research particularities of different specific professional domains language: contrastive studies of terminology (in law, 
economics, marketing, advertising, media, politics, etc.) and its translation. Students offer analysis on the structure, semantics, usage, translation, pronunciation of terms of various professional domains or deal with the aspects of the language for specific purposes in fiction (e.g., polysemy of English legal terms in novels).

Thus, the programme aims at training the language specialists who have both general philological education and highly developed language and communication for specific purposes competences and skills. This applied nature of the programme makes it unique in Lithuania. Its profile is discussed in detail in the following part of the paper.

\subsection{The profile of the $E S P S F L$ study programme}

The ESPSFL programme subjects fall under two major categories: basic philology studies (English and second foreign language) and applied studies (studies of English and second foreign language for specific purposes and translation). General higher education subjects as Introduction to Studies and Philosophy are also mandatory. The study field subjects consist of three subgroups: 1) subjects of General English and the second foreign language - Modern English, Second Foreign Language, Introduction to Linguistics, Contrastive Lexicology and Lexicography, Discourse Analysis; 2) subjects related to ESP and the second foreign language for specific purposes - English Language and Communication for Specific Purposes (for Public Administration, Business, Law, Finance), Theory of Language for Specific Purposes, Basics of Translation, Practical Translation, Translation Technologies, Internship; 3) literary and cultural studies - Basics of Literary Analysis, World Literature, UK and USA Country Studies, Country Studies (France/Germany/Norway/South Korea). A range of elective and alternative subjects is also offered. Students' research competence is developed by a mandatory Term Paper and a Bachelor Thesis.

To deepen the knowledge of specific domains students of the ESPSFL study programme have a possibility to choose minor studies in Public Administration or Business. Each year several students successfully graduate with a major degree in humanities and a minor degree in their chosen field of studies (social sciences). The ESPSFL study programme has also been tailored to the needs of learners in other fields of study and can be chosen as a minor study program by students of Public Administration, Public Policy and Management, and Business. However, in this case the period and intensity of training increases significantly, this factor influencing rather small numbers of undergraduates in minor ESP studies. Nevertheless, the ones who successfully complete the minor ESP studies with additional competencies gain a significant advantage in the labour market.

\section{ON THE INTERNATIONAL ASPECT OF ESPSFL PROGRAMME}

Fostering intercultural communication competence is considered of utmost importance to the ESPSFL study programme students. This competence is developed combining several international aspects of the international student admission and the programme student and teaching staff activities outlined below.

\subsection{International student admission}

Following the launch of the undergraduate ESPSFL study programme, it received considerable interest from the applicants/potential students abroad. It is believed that the 
interest was triggered by the aims of the programme to prepare professionals with both general philological education and highly developed language and communication skills in specific fields, thus being able to contribute to the success of international companies in joint activities, in their communication and cooperation. In 2014 the ESPSFL study programme was open for international student admission and since then it has attracted learners from such far away countries as Japan, China, Israel, Turkey, as well as Northern and Eastern European countries - Norway, Belarus, Russia, Ukraine, and Poland.

\subsection{International teaching staff}

The ESPSFL study programme teaching staff include professional personnel from the USA (K. Schimmels, T. McArthy, as of academic year 2018-2019), The Republic of Ireland (S. O’Donnel), France (A. J. Parent), South Korea (Boa Lim). These and other native speaker professors deliver not only language training courses, but also culture and country studies.

Each year the programme faculty and students host visiting professors from the partner universities in France, Norway, South Korea, Serbia, the Czech Republic, Poland, the USA, the UK, Germany, Portugal, Spain, etc.

Specialists from the European Union institutions (translators, terminologists and lawyers-linguists from the European Commission, Council of the EU and EU Court of Justice) are also invited on annual basis to share their expertise with the ESPSFL students and teaching staff.

\subsection{The role of the ERASMUS+ exchange programme}

The ESPSFL students take active part in the ERASMUS+ exchange programme and study one/two semesters in universities abroad. A substantial number of students opt for internship in foreign organizations and institutions. The most popular choice among a wide range of partner universities which have signed cooperation agreements with MRU in the area of linguistics, philology and translation are studies at National University of Ireland, University of Central Lancashire and University of Lancaster UCLAN (UK), Jean Moulin Lyon 3 University and La Rochelle University in France, Mannheim University (Germany), Agder University and Bergen University in Norway, Cordoba University (Spain), MEF University (Turkey), Busan Dongseo University (South Korea), University of Niš (Serbia) and others.

In a reciprocal manner, substantial numbers of ERASMUS+ students from all over the world come to study in the ESPSFL study programme. Each year we host in-coming students from universities of France, Spain, Italy, Serbia, Turkey, Belarus, China, Germany, South Korea, Taiwan, Japan, Ukraine, Romania, Bangladesh, and Slovakia. Thus, the ESPSFL programme undergraduates enjoy and benefit from studies in a multicultural and multilingual environment.

Teaching staff of the ESPSFL study programme also closely cooperate with ERASMUS+ partner universities, regularly lecturing at foreign universities.

The internship activities of in-coming and on-line Master degree students from partner universities also contribute to the international dimension of the ESPSFL study programme. La Rochelle University (France) interns' activities directly relate to the second foreign- French and Korean- languages studied. They also, together with students of the programme, organize and participate in events at Mykolas Romeris University and social partners thereof. In the academic year of 2018-2019 a new on-line project for the 
optional English language proficiency development was initiated with the MA students at Kingston-upon-Thames, London (UK).

The above mentioned aspects of exposure to multicultural environment and involvement in multifaceted international activities contribute significantly to developing ESPSFL programme student intercultural communication competence.

\section{EMPLOYABILITY OF THE ALUMNI AND THEIR FEEDBACK ON THE ACQUIRED COMPETENCES}

In this section of the paper we aim to highlight the areas of predominant fields of work of the graduates of the ESPSFL study programme and the spheres in which the graduates apply the acquired soft skills and competencies.

It is very gratifying that the active contacts with the alumni are maintained and the first-hand feedback on the gains and shortcomings of the study programme content is offered continuously. The teachers of the programme follow the career paths of the alumni via LinkedIn, personal email/telephone communication, etc. Site visits to the institutions and companies where the programme alumni work are arranged on a regular basis.

With the aim to analyse the extent to which graduates of the ESPSFL study programme apply the acquired soft skills and competencies at work, a qualitative research was conducted. Although the data acquired through the qualitative analysis does not provide precise and reliable statistical data, it enables to establish general tendencies. Since the figures, numbers, frequency and dispersion is considered of little importance in this particular case, the choice was for the qualitative research as it focuses on reflection, interpretation, construing and explanations, all of which expose respondents' motivation, perception and experience intensity (c.f. Bitinas 2008; Neill 2007).

The respondents of the research included 52 alumni of the ESPSFL study programme who found employment after graduation. The data of the study was acquired through interviews with the respondents. The research was based on a questionnaire in the form of open-ended questions. First, respondents were asked to indicate the area, domain or sector they are employed in. Next, they were asked to describe their main functions at work and point which languages they use for their work assignments. To establish the extent to which graduates apply the acquired soft skills and competencies obtained during their studies respondents were asked to answer the following block of questions: What competencies acquired through studies in the ESPSFL study programme do you find most useful? Why? What did you have to learn on your own when you started working? Did any of the competencies you acquired through studies in the ESPSFL study programme help you? Respondents were also asked to provide any additional comments they believe are relevant to the question under consideration. The responses were analysed, grouped accordingly and general tendencies established.

The research results reveal that graduates of the ESPSFL study programme are employed in both private and public sector, with the predominance of the former. The main areas/sectors of work of our graduates are the following:

- public institutions (departments for international relations, training and communication);

- tourism agencies;

- media agencies; 
- transport and logistics enterprises;

- manufacturing enterprises (manufacture of furniture, electronic devices, etc.);

- business service enterprises;

- international companies dealing with financial services;

- business networks (chambers of commerce).

The designers and supervisors of the study programme consider the fact that several alumni are at present the university colleagues, mainly working in the International Office of Mykolas Romeris University, particularly eloquent on the competencies fostered and developed throughout the training years.

The respondents pointed out a great variety of work assignments which require highly professional communication competences. The main areas of their functions are listed below. In the public sector they are responsible for the following job-related activities:

- international external communication with foreign partners of institutions, international organisations, organisers of international events (writing and answering e-mail, telephone and face to face communication);

- international internal communication with foreign citizens studying/working at the institution: preparation, updating and dissemination of internal information in foreign languages; consulting and helping to handle various social issues (accommodation, residence permit, etc.);

- organisation of institutional international events: organisation of introductory weeks for international students, reception of international guests and other internationals events, development of an event programme, budget planning, organisation of cultural programme;

- publicising the institution in foreign and native languages: writing reports on institutional events for institutional websites; writing press releases;

- drafting institutional documents in foreign and native languages: administrative documents (e.g. event schedules), contracts, etc.;

- translation: translation of material for institutional websites into foreign languages; translation of institutional documents into foreign languages.

The alumni employed in the private companies referred to a wider range of jobrelated functions that they carry out:

- international external and internal communication with customers/clients abroad, foreign suppliers and colleagues in units of a company in other countries (writing and answering e-mail, telephone);

- participation in professional events: representing a company in exhibitions abroad, meetings with foreign partners and clients;

- translation and drafting of documents/marketing materials;

- data administration: data entry into systems, control and analysis;

- sales and purchase management: search for customers, customer service management, sale of products and services, online trading, search for goods, handling purchase orders, description of goods and their packaging;

- logistics: distribution of goods to sales spots; coordination of delivery of goods in Europe;

- tourism: coordination of tours (booking hotels, restaurants, guiding services, etc.);

- webcast production: handling production of audio and video webcasts; 
- work in business networks (chambers of commerce): membership service management;

- teamwork coordination: collecting data from team members, systematising and analysing them, training new personnel.

It is noteworthy that a few ESPSFL programme alumni went into teaching English both in Lithuania and abroad. Moreover, the graduates working at educational institutions indicated the importance of the acquired international communication skills in their work with international students, e.g., "In my work, the social-communicative competence, acquired during the studies, helps a lot as I work with students from 58 different countries whose level of English and accents are very different".

The majority of the graduates predominantly use English as the working language. Quite a few alumni make use of the second foreign language, since their jobs require communication with customers/suppliers in different countries. Several graduates have learnt yet another foreign - Norwegian and Danish - language responding to the needs of international companies they are employed by. They acknowledge that the acquired linguistic competences during their studies made the learning process easier: "It has been easier and quicker to learn a new language because I knew already the methods of learning a foreign language, I was able to analyse its system and apply the knowledge in practice".

The graduates, who took part in the survey, enumerated several general competences acquired during the studies which were most important when they started their work career. Firstly, they indicated the ability to organise work activities autonomously and perform them individually or in a team, to plan time and to take responsibility. The graduates also emphasised the significance of the competence of information management which has enabled them to work with information sources in new areas of their work and evaluate critically and use practically relevant information. The survey also reveals that the multicultural environment at the university has influenced the graduates' ability to work in international teams and to communicate with foreign partners, clients and suppliers abroad.

All respondents emphasised the significance of competences of languages for specific purposes. The ability to use foreign languages for specific purposes (especially, business) is of immense importance for the alumni employers. Proficiency in general language and solid knowledge of the field specific terminology is stressed as essential requisite in communication with clients. The following quotation from the alumni responses illustrates the necessity: "Language for specific purposes is especially important in starting contact with new clients. Proper language skills show respect to the client and our proficiency. The first impression determines the client's attitude towards us. Thus, future relations with the client may depend a lot on the first telephone conversation".

The graduates also indicated that acquisition of terminology of new fields has been easier as they had had extensive experience in terminology studies. Though translation does not constitute a considerable part of the graduates' work, several of the respondents mentioned that ability to work with terminology databases, corpora, translation software and other digital translation tools acquired during the studies is of considerable importance in their work. The responses also reveal that the graduates are satisfied that the study programme provided them not only with professional communication abilities, but also with the basics of business/economics and law which are needed in various work assignments as seen from the following: "Skills of languages for specific purposes, basics of law, specific terminology, as well as information management abilities, are very useful as 
I have to follow legislative changes related to the legal status of foreigners in Lithuania and provide information to foreign citizens on documentation and procedures needed for application of residence permit in Lithuania".

The ESPSFL study programme alumni also emphasise that these studies gave them "self-confidence in communication in foreign languages, ability to express one's ideas in written form, to smoothly organise and articulate one's thoughts, analytical skills" and they point to the application of hands-on study tasks (such as drafting documents, making oral presentations, taking part in business meetings, translation and editing) in real life working situations.

Quite a few of graduates combine their working career with further Master degree studies which are mainly within the field of social sciences - logistics management, organisation management, international business communication - both at Alma Mater, Vilnius University or universities abroad, while others continue studies in humanities and arts.

\section{CONCLUSIONS}

It is a common knowledge that English has become the international language of business, media, science and other spheres of international communication. However, the general English philology studies do not satisfy the needs of the main stock holders graduates, who voice the necessity to have, at least, basic knowledge of the specific field and its terminology, and employers, for whom the additional training costs and the need to have multilingual staff with the working proficiency in the second or third language is pressing. Taking these and similar factors into consideration, after surveying the main players in the labour market of Lithuania, the Institute of Humanities at Mykolas Romeris University in 2012 undertook the risk to create and launch a unique in the Lithuanian settings BA programme of English for Specific Purposes and the Second Foreign Language which from the very outset provides training in English for law, business, public administration and related fields.

The programme focuses on fostering multilingual, English for Specific Purposes and professional communication, as well as intercultural communication competencies. ESPSFL has been successful in attracting both Lithuanian and foreign students who enrol wishing to acquire, besides general philology education, particular language skills for highly specific academic or professional reasons.

ESPSFL BA study programme is also tailored and opened as a minor studies programme for students majoring in law, business and public administration, communication. Within several years of the successful implementation a greater choice of second languages has been offered, namely, Korean, Norwegian, German, Spanish and French.

Within the alumni career monitoring system the employment rate and feedback from the graduates and their employers is constantly assessed. It testifies the success of the BA programme in the area of ESP as it addresses the needs to provide its graduates with the indispensable multilingual, intercultural and professional communicative competencies. 


\section{REFERENCES}

Aronin, Larissa and David Singleton. 2012. Multilingualism. Amsterdam, Philadelphia: John Benjamins Publishing Company.

Bitinas, Bronislovas. 2008. Kokybiniu tyrimu metodologija (Methodology of Qualitative Analysis). Socialinių mokslų kolegija. Klaipèda.

Belcher, Diane (Ed.). 2009. English for Specific Purposes in Theory and Practice. Ann Arbor: University of Michigan Press.

Description of the programme English for Specific Purposes and the Second Foreign Language https://stdb.mruni.eu/studiju_programos_aprasas.php?id=10625\&l=en

Janulevičienė, Violeta and Sigita Rackevičienè. 2012. Multilingualism as a core instrument for economic prosperity. Lithuanian employers and employees perspective on the need for new study programmes in applied philology. Societal innovations for global growth: research papers. No. 1(1), p. 939-948. Vilnius: Mykolo Romerio universitetas.

Maher, John C. 2017. Multilingualism. A Very Short Introduction. Oxford: Oxford University Press.

Multilingualism: an asset for Europe and a shared commitment (2008) - Communication from the Commission to the European Parliament, the Council, the European Economic and Social Committee and the Committee of the Regions. http://ecspm.org/wp-content/uploads/2016/04/EU-Multilingualism-Policy_2008.pdf

Neill, J. Salkind. 2007. Qualitative versus Quantitative Research: Key Points in a Classic Debate. http://wilderdom.com/research/QualitativeVersusQuantitativeResearch.html

Stojković, Nadežda. (Ed.) 2018. Convergence of ESP with Other Disciplines. Vernon Press, Spain/USA. 